\title{
Unbalance of Se and nutritional status in male infertility
}

\author{
Luana Mara Silva de Castro Pacheco da Cunha ${ }^{1}$, Maria Yasmin Paz Teixeira ${ }^{1}$, Ana Filomena Camacho Santos \\ Daltro ${ }^{1}$, Sebastião Evangelista Torquato Filho' ${ }^{2}$, Renata Carmo de Assis ${ }^{1}$, Roberta Freitas Celedonio ${ }^{1}$, Liliane \\ Viana Pires ${ }^{3}$, Carla Soraya Costa Maia ${ }^{1}$, Maria Izabel Florindo Guedes ${ }^{1}$
}

${ }^{1}$ Nutrition department, State University of Ceará, Fortaleza, CE, Brazil

${ }^{2}$ Reproduction Human Center Evangelista Torquato, Fortaleza, CE, Brazil

${ }^{3}$ Nutrition department, Federal University of Sergipe, Aracaju, SE, Brazil

\begin{abstract}
Objective: To evaluate the selenium status and oxidative stress in male infertility cases selected from a private human reproduction center in the state of Ceará, Brazil.

Methods: The present study had a cross-sectional quantitative approach, carried out between January and October 2013 at a Human Reproduction Center. The studied population was composed of 49 male individuals seen at the clinic, aged between 18 and 60 years. Blood samples were collected to measure serum selenium concentrations, erythrocyte activity and glutathione peroxidase. After medical diagnosis, the participants were divided into fertile and infertile groups. Blood samples were collected for establishing Se concentrations in plasma and erythrocytes, and measurements of the enzymatic activity of glutathione peroxidase in the erythrocytes.

Result: it resulted in $53.1 \%$ of fertile men and $46.9 \%$ of infertile men. The average age of the fertile group was 34.1 years and the infertile group was 37.3 years. Regarding the assessment of nutritional status, the scatter diagram of the infertility group showed a higher body mass index and waist circumference, showing that this group has a higher risk of global and abdominal obesity compared to the fertile group $(p<0.0001$, respectively). There were similarities between the groups regarding caloric intake, macronutrient and selenium intake.

Conclusion: We can conclude that the serum values of selenium, in excess and in deficiency, can be harmful to male fertility.
\end{abstract}

Keywords: male infertility, selenium, oxidative stress, overweight

\section{INTRODUCTION}

Infertility is defined as the inability of a couple to achieve conception or to bring a pregnancy to term after one year or more of regular, unprotected intercourse, and it has been recognized as a public health problem worldwide (World Health Organization - WHO, 2000; Agarwal et al., 2015). It affects $10-15 \%$ of couples in reproductive age (Winters \& Walsh, 2014). Some studies show that environmental, physiological and genetic factors are related to $25 \%$ of male factor infertility due to semen quality, including oxidative stress, which has frequently been associated with the problem (Kolesnikova et al., 2015; Aitken, 2016).

Oxidative stress adversely affects sperm function by altering membrane fluidity, permeability and sperm functional competence (Kumar \& Singh, 2018; Riaz et al., 2016; Aitken et al., 2016). Sperm membranes are characterized by relatively greater concentrations of polyunsaturated fatty acids that are extremely sensitive to the attack of reactive oxygen species (ROS) (Treulen et al., 2015). Oxidative stress attacks not only the fluidity of the sperm plasma membrane, but also the deoxyribonucleic acid (DNA) integrity in the sperm nucleus, making the sperm unable to fertilize an egg or start a viable pregnancy (Bisht \& Dada, 2017; Hashemi et al., 2018).

Essential trace minerals such as selenium (Se) not only act as antioxidants but also play vital roles in multiple metabolic processes (Türk et al., 2014; Ahsan et al., 2014). Se is an essential trace mineral recognized as fundamental for human reproduction, spermatogenesis, promotion of normal testicular development and preserving spermatozoa motility (Adeoye et al., 2018).

One of Se's biochemical functions is linked to the enzyme glutathione peroxidase (GPx), a selenoprotein with an antioxidant function that protects the sperm membrane against oxidative stress. GPx acts as an Se reservoir, which is used in emerging needs. Due to its powerful antioxidant effect, $\mathrm{Se}$ in the GPx needs to be better investigated as a nutritional factor for the protection of men's health in relation to male infertility, considering that oxidative stress compromises sperm motility, vitality and function (Qazi et al., 2019).

The primary source of Se for men is through food. Thus, the Se present in foodstuff can be influenced by the environment and soils, especially those with a high concentration of Se, which can theoretically produce foods richer in this nutrient, enabling its adequate intake. Based on this, the consumption of this mineral in Brazilian diets varies according to region (Tureck et al., 2017).

Since $\mathrm{Se}$ is a mineral essential for improving reproductive health and Ceará (state of Brazilian Northeast) has a Se-rich soil, the present study's goal was to evaluate Se, nutritional status and their association with human reproduction in Fortaleza, Ceará- Brazil.

\section{MATERIAL AND METHODS \\ Study design}

The present study was a quantitative cross-sectional approach, carried out between January and October of 2013 at a Human Reproduction Center in Fortaleza, capital of the state of Ceará, Brazil. The studied population consisted of male individuals seen at the clinic, aged between 18 and 60 years without chronic diseases, non-smokers, without the use of vitamin and mineral supplements and hormonal medications. The study was conducted according to the ethical principles and guidelines for the protection of human participants in research, which was approved by the Ethics Committee for research of the State University of Ceará (protocol number 5882212.9.00005534 issued on 27/12/2012). 


\section{Data collection}

We collected sociodemographic data to characterize the sample. Weight $(\mathrm{kg})$ and height $(\mathrm{m})$ were measured according to the Frisancho methodology (Frisancho, 1990). We calculated the Body Mass Index (BMI) by dividing the body weight by height $\left(\mathrm{kg} / \mathrm{m}^{2}\right)$. Nutritional diagnosis was assessed according to the classification for adults (WHO, 2000). Waist circumference (WC) was measured using a flexible, tension-sensitive, non-stretchable measuring tape (Gulick II) placed directly onto the skin. Measurements were taken from the midpoint between the iliac crest and the lowest rib (WHO, 2011).

We assessed dietary intake using the 24-h recall method. Three non-consecutive 24-h dietary recalls were collected, which included two weekdays and one weekend day (Fisberg et al., 2005). We used the computer software NutWin (version 2.5, 2002) (fed with the USDA database); the UNIFESP-EPM was used for food intake calculation, with adequacy established by the Dietary Reference Intakes (DRIs) (Institute of Medicine - IOM, 2005). The amounts indicated by the subjects were transformed into homemade measures and analyzed (Pinheiro et al., 2008). The Se values were adjusted for energy (IOM, 2000).

Semen analysis was completed by an accredited laboratory according to the standards set by the WHO (2010), which consisted of the macroscopic and microscopic evaluations of the semen.

After medical diagnosis, the participants were divided into fertile and infertile groups. Blood samples were collected for the determination of Se concentrations in plasma and erythrocytes, and we measured their glutathione peroxidase (GPx) enzymatic activity in erythrocytes.

The plasma and erythrocyte Se levels were determined by atomic absorption spectrometry using the hydride generation coupled to the quartz cell HITACHI (Z-5000 model), adapted from Martens et al. (2015). GPx activity in erythrocyte was assessed using the kinetic method described by Paglia \& Valentine (1967).

We used the commercially available kit (RANSEL 505 RANDOX Laboratories Ltd, UK - reference range: 27.5 to $73.6 \mathrm{U} / \mathrm{g} \mathrm{Hb}$ ) according to the manufacturer's instructions.

\section{Statistical analysis}

We processed the data using the free software $R$ (version 2.15.0). To compare the mean parameters of the fertile and the infertile groups, we used the Student t-test and ANOVA, and in both cases, we obtained the p-value by the exact test via Bootstrap, ensuring the robustness against the lack of normality. To correlate dietary intake of Se and dietary energy, we used the Kolmogorov - Smirnov test and applied the Pearson's correlation to assess whether there was a statistically significant correlation between energy and Se. After that, we ran a linear regression analysis between the energy (independent variable) and Se (dependent variable) to make the adjustment for energy. All analyses were considered statistically significant if $p<0.05$.

\section{RESULTS}

We assessed the fertility of 50 male subjects. One participant left the study, yielding $53.1 \%$ fertile men and $46.9 \%$ infertile men. The mean age of the fertile group was 34.1 (7.6) years and the infertile group was $37.3(8.1)$ years.

Regarding nutritional status assessment, the scatter diagram of the infertility group showed higher BMI and WC, showing that this group presents a higher risk of global and abdominal obesity as compared to the fertile group $(p<0.0001$, respectively) (Table 1$)$ (Figure 1$)$. There were similarities between the groups regarding caloric intake and that of macronutrients and Se (Table 1).

There was no significant difference for serum Se (Table 1). According to Van Dael \& Deelstra (1993), the plasma values should be in the range of 60 to $120 \mu \mathrm{g} / \mathrm{L}$. In this sense, $42.31 \%$ of the fertile and $56.52 \%$ of the infertile were within this range. In the infertile group, the mean selenium concentration in erythrocytes was higher than in the fertile group (Table 1 ). According to Van Dael \& Deelstra (1993), the reference value of the erythrocyte Se should be in the range of $90-190 \mu \mathrm{g} / \mathrm{L}$. We had $42.31 \%$ of the subjects in the fertile group and $56.52 \%$ of the infertile group within this range.

Table 1. Anthropometric, dietary, biochemical analyses and antioxidants enzymes of the study subjects (Mean values and standard deviations)

\begin{tabular}{|c|c|c|c|c|c|}
\hline & \multicolumn{2}{|c|}{ Fertile $(n=26)$} & \multicolumn{2}{|c|}{ Infertile $(n=23)$} & \multirow{2}{*}{$\boldsymbol{p}$} \\
\hline & Mean & SD & Mean & SD & \\
\hline \multicolumn{6}{|l|}{ Subject characteristics } \\
\hline Waist circumference $(\mathrm{cm})$ & 90.88 & 10.16 & $96.02 * *$ & 11.07 & $<0.0001$ \\
\hline Body mass index $\left(\mathrm{kg} / \mathrm{m}^{2}\right)$ & 26.48 & 3.61 & $28.48 * *$ & 3.97 & $<0.0001$ \\
\hline \multicolumn{6}{|l|}{ Food and selenium intake } \\
\hline Energy (kcal/day) & 3259.59 & 1092.40 & 3126.20 & 927.81 & 0.6494 \\
\hline Protein (kcal/day) & 18.55 & 3.13 & 20.10 & 6.05 & 0.2287 \\
\hline Carbohydrate (kcal/day) & 48.38 & 7.18 & 47.25 & 8.43 & 0.5304 \\
\hline Lipid (kcal/day) & 32.44 & 6.53 & 32.20 & 5.89 & 0.8939 \\
\hline Selenium ( $\mu \mathrm{g} /$ day) & 62.91 & 25.06 & 56.08 & 17.40 & 0.2795 \\
\hline \multicolumn{6}{|c|}{ Biochemical analysis ( $\mu \mathrm{g} / \mathrm{L})$} \\
\hline Plasmatic selenium & 59.26 & 10.02 & 62.46 & 12.34 & 0.3206 \\
\hline Erythrocyte selenium & 87.75 & 48.73 & $101.75 *$ & 71.12 & 0.0301 \\
\hline \multicolumn{6}{|c|}{ Antioxidants enzymes (U/g Hb) } \\
\hline Erythrocyte GPx & 55.88 & 13.49 & 61.45 & 20.92 & 0.5144 \\
\hline
\end{tabular}

GPx: Glutathione Peroxidase; SD: standard deviation; Bold values signify that significance level 0.05 was used for statistical interference. $* p<0.05 ; * p<0.01$ 
Fertile

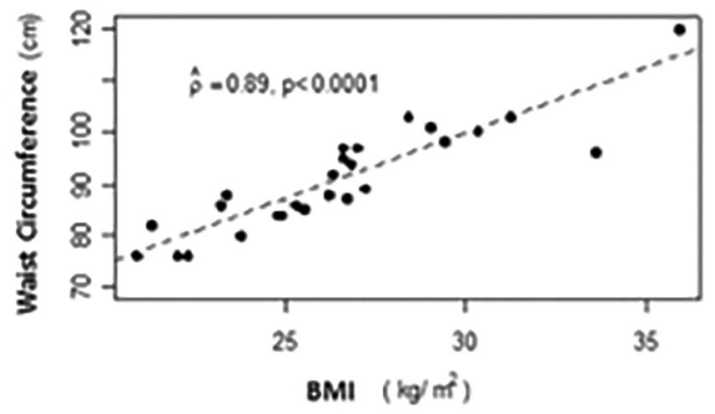

Infertile

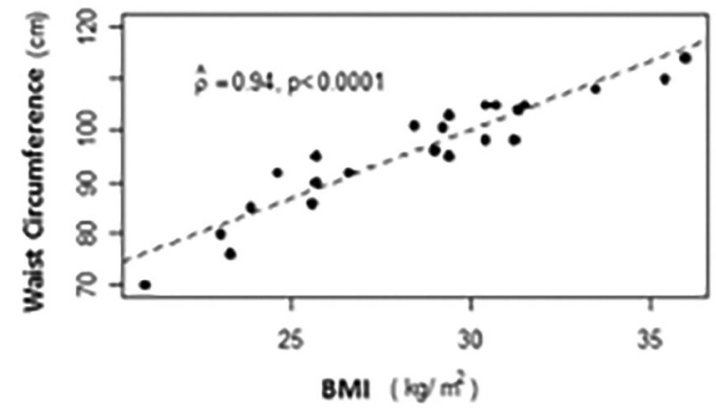

Figure 1. Scatter plot between waist circumference $(\mathrm{cm})$ and body mass intake $\left(\mathrm{Kg} / \mathrm{m}^{2}\right)$ by group

There was a positive correlation between Se intake and motility index $(\%)(p=0.0407)$ at the $5 \%$ level. The higher the intake of $\mathrm{Se}$, the higher the motility index (\%) in the fertile group. (Figure 2). However, there was a negative correlation between WC and Se intake ( $g /$ day) in the infertile group $(r=-0,42 p=0.0456)$ (Figure 3$)$.

On the other hand, there was a significant negative linear correlation $(p<0.0001)$ between the Kruger morphology $(\%)$ and serum Se in the fertile group. Thus, the higher the plasma Se levels in this group, the lower the Kruger morphology (\%) (Figure 4).

Another result of the Kruger's strict sperm morphology (\%) showed a significant positive linear correlation $(p=0.0081)$, at the $5 \%$ level, with the motility index $(\%)$ in infertile men (Figure 5).

Between groups there was no difference in GPx activity (Table 1$)$. In addition, there was a positive correlation $(p=0.0305)$ between ejaculate volume and GPx in the infertile group (Figure 6 ).

\section{DISCUSSION}

Selenium biomarkers were associated with male fertility because among fertile men, serum Se levels was inversely associated with the Kruger morphology rate (\%), and among the infertile, erythrocyte Se was at higher levels, revealing that serum selenium imbalance, both excess and reduction influence male fertility. GPx activity, also called GPx1, was preserved in both groups without statistical difference between them. Fertile and infertile men were studied for Se concentrations (plasm and erythrocyte).

Trace elements such as selenium are involved in many vital reproductive health and performance processes. However, studies are scarce on the concentration of Se in various body fluids/tissues for optimal reproductive performance. Adequate concentrations of this mineral in the reproductive tissues are fundamental for several processes associated with fertility such as spermatogenesis, maturation and motility of spermatozoids, besides maintenance and improvement of GPx antioxidant activity. Some selenoenzymes such as selenoprotein P (SelP) and the GPx family (especially the GPx 4 isoform) are involved in fertility and reproductive processes (Qazi et al., 2019). Thomson (2004) stated that the consumption of $45-50 \mu \mathrm{g} /$ day is able to optimize the activity of GPx and SelP. Thus, considering the consumption from both groups in this study we can justify the appropriate activity of the GPx enzyme in these groups (Thomson, 2004).
The selenium from food is rich in organic forms of this mineral which has been related to better assimilation being more bioavailable and less toxic. Vitamin $B_{6}$ also participates in the optimization of the GPx system from organic forms of selenium. Therefore, proper nutrition can contribute to fertility. Consumption and adequate concentrations of selenium are linked to testosterone biosynthesis whose mechanism is related to the expression and antioxidant action of SelP in the cells of Leydig and cytosolic GPx acting on the neutralization of $\mathrm{H}_{2} \mathrm{O}_{2}$ produced in this biosynthesis (Qazi et al., 2019).

Se deficient and Se excess diets have been reported to result in reduced spermatozoa motility, concentration, and fertility. Diets excessive or deficient in Se affect the gross as well as histological morphology of the testis. Sperm morphology is considered one of the most important seminal parameters, being the best indicator of male fertility. At appropriate levels of serum Se, sperm morphology presents good quality, but as there is inadequacy in consumption, that is, it exceeds the recommended value, this morphology becomes impaired. Therefore, although sperm morphology is a controversial parameter, it is an important result regarding the fertility of men who underwent antioxidant treatment (Qazi et al., 2019).

Studies observed by Riaz et al. (2016) and Lovercamp et al. (2013) show that high levels of plasma Se resulted in a sperm morphology reduction and consequently its motility in fertile men. Our results are consistent with the findings and the same effect was observed in the fertile group. According to WHO (2010), the strict Kruger morphology criteria has a directly association to motility. In the infertile group, the mean erythrocyte Se value was higher than the fertile.

These data suggest that elevated levels of erythrocyte Se decrease motility because the effect of motile onset was probably mediated by secretions of accessory sex glands or during sperm maturation or ejaculation, since there was little evidence of toxic effect upon ingestion (Dorostghoal et al., 2017).

Although no difference in food intake was found between groups analysed, the fertility group showed a positive correlation between Se intake and sperm motility (\%). These results are in agreement with Foresta et al. (2002), Klein (2004), Moslemi \& Tavanbakhsh (2011) that showed the relationship between Se ingestion and increased sperm motility.

Besides that, there was a positive correlation between ejaculate volume and GPx in a fertile group. This is in accordance with the study of Türk et al. (2014) 
Fertile

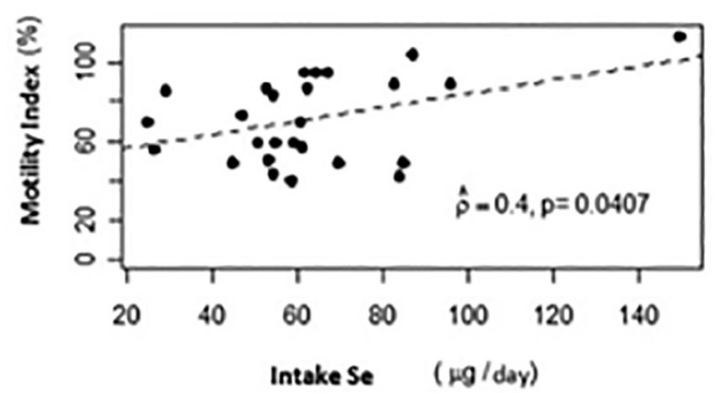

Infertile

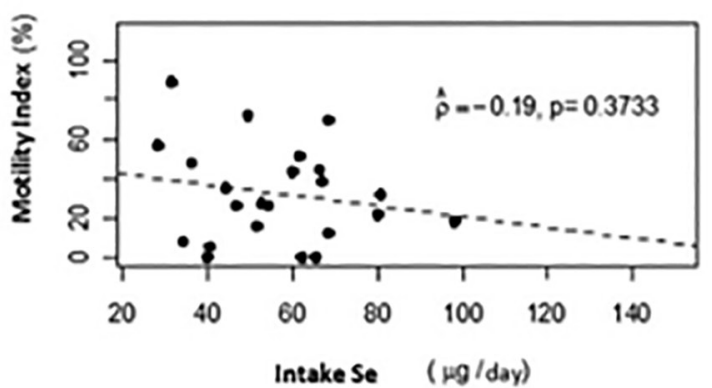

Figure 2. Scatter plot between motility index $(\%)$ and intake Se $(\mu \mathrm{g} / \mathrm{day})$ by group

Fertile

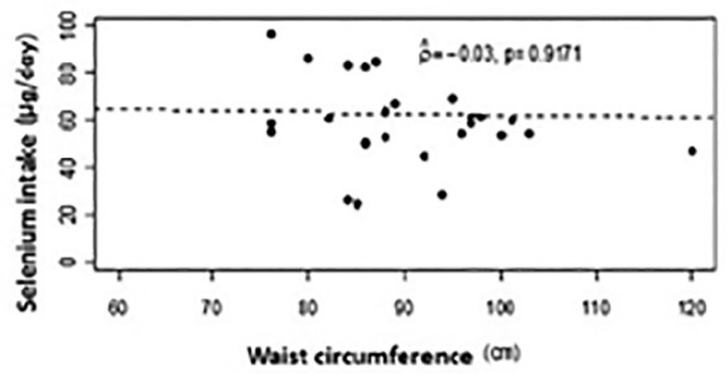

Infertile

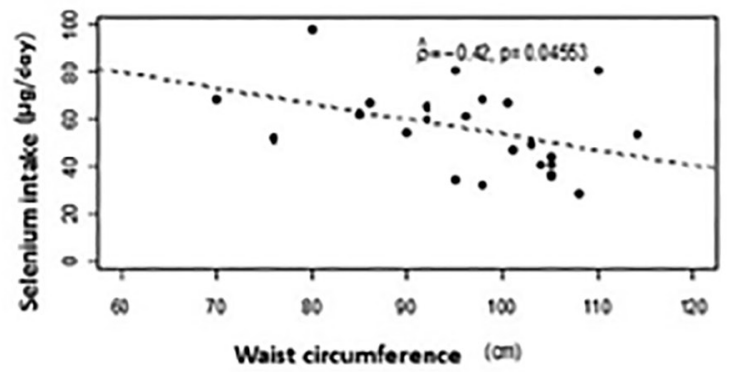

Figure 3. Scatter plot between selenium intake $(\mu \mathrm{g} /$ day $)$ and waist circumference $(\mathrm{cm})$ by group

Fertile

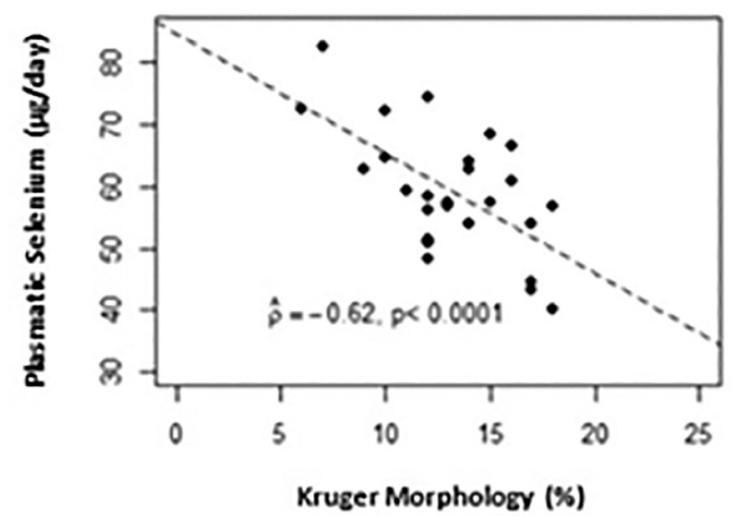

Infertile

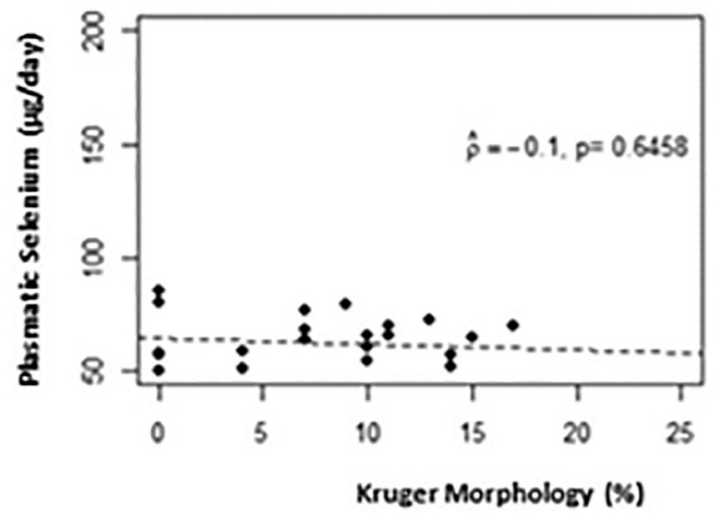

Figure 4. Scatter plot between plasmatic selenium ( $\mu \mathrm{g} / \mathrm{day})$ and Kruger morphology (\%) by group

confirming the presence of GPx in the ejaculate mainly coming from the testes and epididymis, thus regulated by the ingestion of Se.

Thus, decreased GPx activity during Se deficiency and increased lipid peroxidation, indicate increased levels of free radicals which disrupts the normal spermatogenic process and might be responsible for reduced sperm motility and viability leading to reduced fertility and fewer litters. The GPx is responsible for over $75 \%$ of antioxidant activity in spermatozoa. In Se excess, increased lipid peroxidation could be attributed to the ability of selenite to form a highly reactive species, a selenopersulfide which generates free radical, superoxide as well as other Reactive Oxygen Species (Shalini \& Bansal, 2007; Shalini \& Bansal, 2008).

Besides these aspects, it can be verified that the nutritional status indicated higher levels of BMI and WC in the infertile group. Obesity seems to have a deleterious effect on semen quality by changes in epididymal function, reducing the biomarkers of normal accessory gland function. In addition, the ejaculated volume $(\mathrm{mL})$, sperm concentration (million/mL), 
Fertile

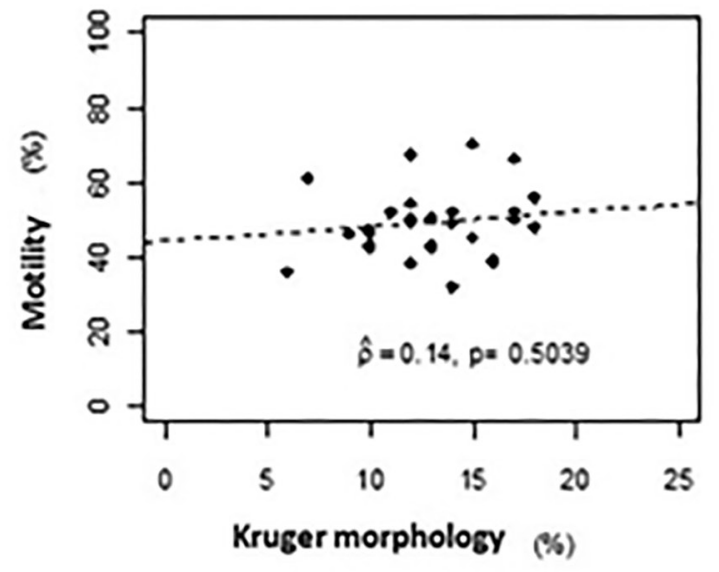

Infertile

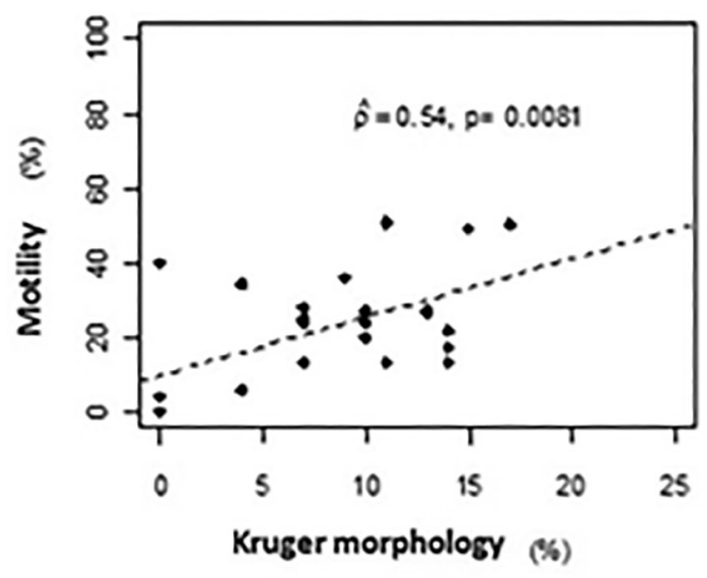

Figure 5. Scatter plot between motility (\%) and Kruger morphology (\%) by group
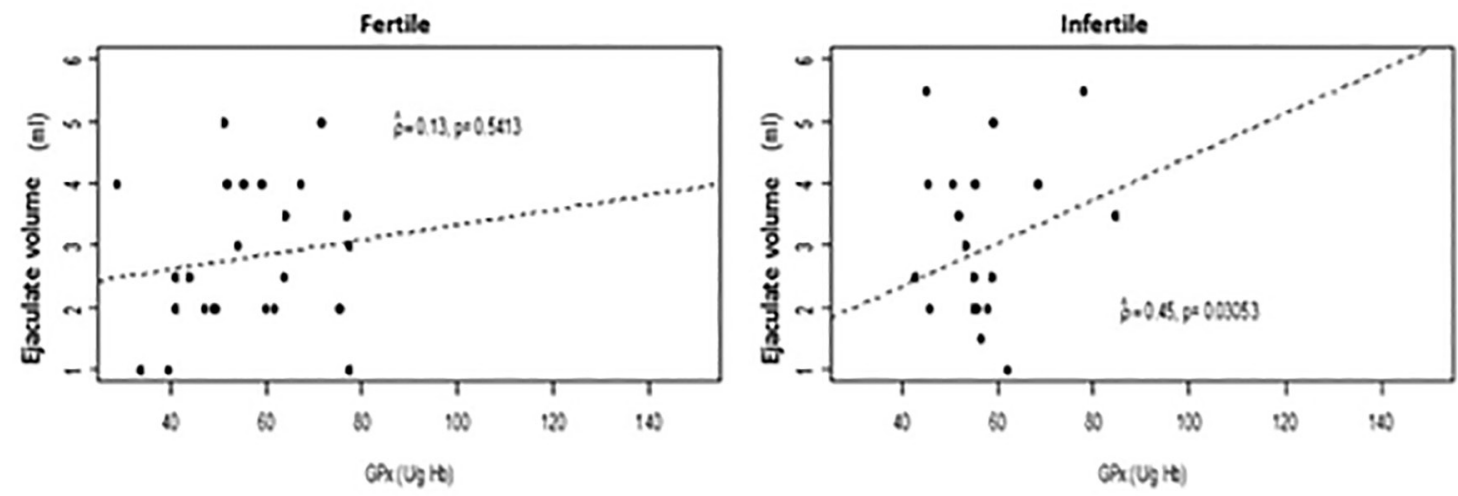

Figure 6. Scatter plot between ejaculate volume $(\mathrm{ml})$ and $\mathrm{GPx}(\mathrm{Ug} / \mathrm{Hb})$ by group

and total sperm count (millions / ejaculate) are inversely correlated with BMI. Obese men were 19 times more likely to have a lower total sperm count (millions / ejaculate) than eutrophic (Bieniek et al., 2016; Oliveira et al., 2017; Wang et al., 2017; Liu \& Ding, 2017). The results are similar to studies designed by Borges Jr. et al. (2015) and Schlichthorst et al. (2016) that showed a relationship of obesity and infertility with men with mean age of 37 years. The increased WC is associated with obesity-related health risk that can reduce male fertility (Hayden et al., 2018; Kasum et al., 2016). Se may be a protective factor in male fertility, since the higher the Se intake, the smaller the waist circumference is in the infertile group, and higher the sperm motility index in the fertile group.

Our study demonstrates the possible interferences of obesity, deficiency and excess selenium in male fertility. Thus the action of dietary selenium appears to be $\mathrm{U}$-shaped with respect to reproductive capacity and its markers. Further studies are needed to clarify the mechanisms involved in this process. It also makes an important contribution by calling attention to the use of supplements with Se megadoses present in antioxidant treatments.

\section{CONCLUSION}

From the above findings, we can conclude that fertile and infertile men were suitable for Se concentrations. Serum values of Se, both excess and deficiency can be detrimental to male fertility. In the fertile group, Se consumption was positively correlated with sperm motility and, in the infertile group, negatively correlated with WC.

\section{ACKNOWLEDGMENT}

The authors would like to thank the Torquato Evangelista Human Reproduction Center, the Laboratory of Biochemistry and Food Analysis of the State University of Ceara - UECE; the Laboratory of Mineral Nutrition of the University of São Paulo - USP, the Center for Experimental Biology of the University of Fortaleza - UNIFOR, the Laboratory of Pharmacology of Inflammation and Cancer - LAFICA and the Pasteur Diagnostic Laboratory for support in the development of the research.

\section{CONFLICT OF INTEREST}

The authors have no conflicts of interest to declare. 
Corresponding author:

Carla Soraya Costa Maia

Nutrition department

State University of Ceará

Fortaleza, Ceará, Brazil.

E-mail: carla.maia@uece.br

\section{REFERENCES}

Adeoye O, Olawumi J, Opeyemi A, Christiania O. Review on the role of glutathione on oxidative stress and infertility. JBRA Assist Reprod. 2018;22:61-6. PMID: 29266896 DOI: 10.5935/1518-0557.20180003

Agarwal A, Mulgund A, Hamada A, Chyatte MR. A unique view on male infertility around the globe. Reprod Biol Endocrinol. 2015;13:37. PMID: 25928197 DOI: 10.1186/ s12958-015-0032-1

Ahsan U, Kamran Z, Raza I, Ahmada S, Babar W, Riaz MH, Iqbal Z. Role of selenium in male reproduction - a review. Anim Reprod Sci. 2014;146:55-62. PMID: 24613013 DOI: 10.1016/j.anireprosci.2014.01.009

Aitken RJ. Oxidative stress and the etiology of male infertility. J Assist Reprod Genet. 2016;33:1691-2. PMID: 27544275 DOI: $10.1007 / s 10815-016-0791-4$

Aitken RJ, Gibb Z, Baker MA, Drevet J, Gharagozloo P. Causes and consequences of oxidative stress in spermatozoa. Reprod Fertil Dev. 2016;28:1-10. PMID: 27062870 DOI: $10.1071 /$ RD15325

Bieniek JM, Kashanian JA, Deibert CM, Grober ED, Lo KC, Brannigan RE, Sandlow JI, Jarvi KA. Influence of increasing body mass index on semen and reproductive hormonal parameters in a multi-institutional cohort of subfertile men. Fertil Steril. 2016;106:1070-5. PMID: 27460460 DOI: 10.1016/j.fertnstert.2016.06.041

Bisht S, Dada R. Oxidative stress: Major executioner in disease pathology, role in sperm DNA damage and preventive strategies. Front Biosci (Schol Ed). 2017;9:420-47. PMID: 28410127 DOI: $10.2741 /$ s495

Borges E Jr, Setti AS, Braga DP, Figueira Rde C, Iaconelli A Jr. Decline in semen quality among infertile men in Brazil during the past 10 years. Int Braz J Urol. 2015;41:75763. PMID: 26401870 DOI: 10.1590/S1677-5538. IBJU.2014.0186

Dorostghoal M, Kazeminejad SR, Shahbazian N, Pourmehdi M, Jabbari A. Oxidative stress status and sperm DNA fragmentation in fertile and infertile men. Andrologia. 2017;10:e12762. PMID: 28124476 DOI: 10.1111/ and. 12762

Fisberg RM, Martini LA, Slater B. Métodos de inquéritos alimentares In: Fisberg RM, Slater B, Marchioni DML, Martini LA, eds. Inquéritos alimentares: métodos e bases científicos. São Paulo: Manole; 2005. p. 1-31.

Foresta C, Bettella A, Merico M, Garolla A, Ferlin A, Rossato $M$. Use of recombinant human follicle-stimulating hormone in the treatment of male factor infertility. Fertil Steril. 2002;77:238-44. PMID: 11821078 DOI: 10.1016/ S0015-0282(01)02966-1
Frisancho AR. Anthropometric standards for the assessment of growth and nutritional status. Ann Arbor: University of Michigan Press; 1990.

Hashemi MM, Behnampour N, Nejabat M, Tabandeh A, Ghazi-Moghaddam B, Joshaghani HR. Impact of Seminal Plasma Trace Elements on Human Sperm Motility Parameters. Rom J Intern Med. 2018;56:15-20. PMID: 28865234 DOI: $10.1515 / \mathrm{rjim}-2017-0034$

Hayden RP, Flannigan R, Schlegel PN. The Role of Lifestyle in Male Infertility: Diet, Physical Activity, and Body Habitus. Curr Urol Rep. 2018;19:56. PMID: 29774489 DOI: 10.1007/s11934-018-0805-0

IOM - Institute of Medicine (US) Panel on Dietary Antioxidants and Related Compounds. Dietary Reference Intakes for Vitamin C, Vitamin E, Selenium, and Carotenoids. Washington, DC: National Academies Press (US); 2000.

IOM - Institute of Medicine. Dietary Reference Intakes for Energy, Carbohydrate, Fiber, Fat, Fatty Acids, Cholesterol, Protein, and Amino Acids. Washington, DC: National Academies Press; 2005.

Kasum M, Anić-Jurica S, Čehić E, Klepac-Pulanić T, Juras J, Žužul K. Influence of male obesity on fertility. Acta Clin Croat. 2016;2:301-8. PMID: 28394547 DOI: 10.20471/ acc. 2016.55.02.18

Klein EA. Selenium: epidemiology and basic science. J Urol. 2004;17:S50-3. PMID: 14713754 DOI: 10.1097/01. ju.0000107837.66277.e9

Kolesnikova LI, Kolesnikov SI, Kurashova NA, Bairova TA. Causes and factors of male infertility. Vestn Ross Akad Med Nauk. 2015;70:579-84. PMID: 26846084 DOI: 10.15690/ vramn.v70.i5.1445

Kumar N, Singh AK. Reactive oxygen species in seminal plasma as a cause of male infertility. J Gynecol Obstet Hum Reprod. 2018;47:565-72. PMID: 30016715 DOI: 10.1016/j.jogoh.2018.06.008

Liu Y, Ding Z. Obesity, a serious etiologic factor for male subfertility in modern society. Reproduction. 2017;154:R12331. PMID: 28747541 DOI: 10.1530/REP-17-0161

Lovercamp KW, Stewart KR, Lin X, Flowers WL. Effect of dietary selenium on boar sperm quality. Anim Reprod Sci. 2013;138:268-75. PMID: 23523235 DOI: 10.1016/j.anireprosci.2013.02.016

Martens IB, Cardoso BR, Hare DJ, Niedzwiecki MM, Lajolo FM, Martens A, Cozzolino SM. Selenium status in preschool children receiving a Brazil nut-enriched diet. Nutrition. 2015;11:1339-43. PMID: 26429652 DOI: 10.1016/j. nut.2015.05.005

Moslemi MK, Tavanbakhsh S. Selenium-vitamin E supplementation in infertile men: effects on semen parameters and pregnancy rate. Int J Gen Med. 2011;4:99-104. PMID: 21403799 DOI: $10.2147 /$ IJGM.S16275

Oliveira PF, Sousa M, Silva BM, Monteiro M, Alves MG. Obesity, energy balance and spermatogenesis. Reproduction. 2017;153:R173-85. PMID: 28283671 DOI: 10.1530/ REP-17-0018 
Paglia DE, Valentine WN. Studies on the quantitative and qualitative characterization of erythrocyte glutathione peroxidase. J Lab Clin Med. 1967;70:158-69. PMID: 6066618

Pinheiro ABV, Lacerda EMA, Benzecry EH, Costa VM, Gomes MCS, eds. Tabela para avaliação de consumo alimentar em medidas caseiras. 4a ed. São Paulo: Atheneu; 2008.

Qazi IH, Angel C, Yang $H$, Zoidis E, Pan B, Wu Z, Ming $Z$, Zeng CJ, Meng Q, Han H, Zhou G. Role of Selenium and Selenoproteins in Male Reproductive Function: A Review of Past and Present Evidences. Antioxidants (Basel). 2019;8:268. PMID: 31382427 DOI: 10.3390/antiox8080268

Riaz M, Mahmood Z, Shahid M, Saeed MU, Tahir IM, Shah $\mathrm{SA}$, Munir N, El-Ghorab A. Impact of reactive oxygen species on antioxidant capacity of male reproductive system. Int J Immunopathol Pharmacol. 2016;29:421-5. PMID: 26684624 DOI: 10.1177/0394632015608994

Schlichthorst M, Sanci LA, Hocking JS. Health and lifestyle factors associated with sexual difficulties in men - results from a study of Australian men aged 18 to 55 years. BMC Public Health. 2016;16:1043. PMID: 28185600 DOI: 10.1186/s12889-016-3705-6

Shalini S, Bansal MP. Alterations in selenium status influences reproductive potential of male mice by modulation of transcription factor NFkappaB. Biometals. 2007;20:49-59. PMID: 16758115 DOI: 10.1007/s10534-006-9014-2

Shalini S, Bansal MP. Dietary selenium deficiency as well as excess supplementation induces multiple defects in mouse epididymal spermatozoa: understanding the role of selenium in male fertility. Int J Androl. 2008:31:438-49. PMID: 17651402 DOI: 10.1111/j.1365-2605.2007.00789.x

Thomson CD. Assessment of requirements for selenium and adequacy of selenium status: a review. Eur J Clin Nutr. 2004;58:391-402. PMID: 14985676 DOI: 10.1038/ sj.ejcn. 1601800
Treulen F, Uribe P, Boguen R, Villegas JV. Mitochondrial permeability transition increases reactive oxygen species production and induces DNA fragmentation in human spermatozoa. Hum Reprod. 2015;30:767-76. PMID: 25662811 DOI: $10.1093 /$ humrep/dev015

Tureck C, Locateli G, Corrêa VG, Koehnlein EA. Evaluation of the Brazilian population's intake of antioxidant nutrients and their relation with the nutritional status. Rev Bras Epidemiol. 2017;20:30-42. PMID: 28513792 DOI: 10.1590/1980-5497201700010003

Türk S, Mändar R, Mahlapuu R, Viitak A, Punab M, Kullisaar T. Male infertility: decreased levels of selenium, zinc and antioxidants. J Trace Elem Med Biol. 2014;28:179-85. PMID: 24462254 DOI: $10.1016 / j . j t e m b .2013 .12 .005$

Van Dael P, Deelstra H. Selenium. Int J Vitam Nutr Res. 1993;63:312-6. PMID: 8157441

Wang EY, Huang Y, Du QY, Yao GD, Sun YP. Body mass index effects sperm quality: a retrospective study in Northern China. Asian J Androl. 2017;19:234-7. PMID: 26732109 DOI: $10.4103 / 1008-682 X .169996$

Winters BR, Walsh TJ. The epidemiology of male infertility. Urol Clin North Am. 2014;41:195-204. PMID: 24286777 DOI: $10.1016 /$ j.ucl.2013.08.006

WHO - World Health Organization. Obesity: preventing and managing the global epidemic. Report of a World Health Organization Consultation. WHO Technical Report Series 894. Geneva: WHO; 2000. Available at: https://www.who. int/nutrition/publications/obesity/WHO_TRS_894/en/

WHO - World Health Organization. Laboratory manual for the examination and processing of human semen. 5th ed. Geneva: WHO; 2010. Available at: https://www.who.int/reproductivehealth/publications/infertility/9789241547789/en/

WHO - World Health Organization. Waist circumference and waist-hip ratio. Report of a WHO expert consultation. Geneva: WHO; 2011. Available at: https://www.who.int/ nutrition/publications/obesity/WHO_report_waistcircumference_and_waisthip_ratio/en/ 